\title{
Psychological factors of ICT competence formation in part-time students of the specialty "Preschool education"
}

\author{
Liubov Lokhvytska ${ }^{1, *}$ and Nataliia Martovytska ${ }^{2, * *}$ \\ ${ }^{1}$ Psychology and Pedagogy of Pre-school Education Department, Hryhorii Skovoroda University in Pereiaslav, 30 Sukhomlynsky Str., \\ Pereiaslav, 08041, Ukraine \\ ${ }^{2}$ Foreign Language Department, The Bohdan Khmelnytsky National University of Cherkasy, 81 Shevchenko Blvd., Cherkasy, 18031, \\ Ukraine
}

\begin{abstract}
The transience of time and the use of information and communication technology (ICT) have led to the urgent necessity - the formation of the educational process subjects' ICT competence. In today's educational sector in Ukraine and foreign countries, the studied phenomenon has acquired special significance. The goal: a) theoretical analysis of various aspects of the individual's ICT competence formation, clarification of the essential content of the concept and offer its working definition; b) figuring out psychological factors of influence and their constructs on the ICT competence formation; determination of criteria, indexes and levels of the studied phenomenon formation; c) empirical study of the influence of psychological factors on the ICT competence formation in applicants for educational services of higher education institutions (part-time students of 2 Ukrainian universities). Conceptually psychological factors which have an influence on the ICT competence formation were characterized. The main criteria of ICT competence were offered, their indexes were defined and the description of levels of formation was given. According to the results of the empirical study the dependence of the influence of various psychological factors on the ICT competence formation in accordance with the pedagogical experience of 187 respondents was found out.
\end{abstract}

\section{Introduction}

Modern changes in the world, due to various transformational processes, both positive and negative, are characterized by challenges, the response to which requires mastering new competencies. The formation of a number of competencies has become one of the main tasks specified in the Law of Ukraine "On Education" [1]. Among the list of such is the competence in the field of information and communication technology (ICT competence), which should be formed in all subjects of the educational process [2]. (Hereinafter referred to as the term ICT competence). Thus, the reform of the educational system, including its first component - preschool education, has raised the issue of future preschool education teachers' ICT competence formation.

The raised problem caused the purpose of carrying out research:

a) realization of the theoretical analysis of a problem of ICT competence formation, specification of the essential maintenance of concept and specification of its working definition (in the general aspects and in a context of the individual's of professional pedagogical activity implementation);

b) clarification of the factors influencing, in particular psychological and their constructs, on the ICT

\footnotetext{
*e-mail: lokhvytska@gmail.com
}

**e-mail: nv.martovytska@gmail.com competence formation, substantiation of the definition criteria, indexes and levels of the studied phenomenon formation;

c) empirical study of the influence of psychological factors on the ICT competence formation of teachers of the first (preschool) component of the Ukrainian education system, in particular part-time students, as specialists who lay the foundation of a child's growing personality.

Modern scholars have studied various aspects of the individual's ICT competence formation:

- the use of ICT to improve the quality of the educational process, in particular, the introduction of digital literacy and the study of effectiveness [3-8];

- creation of information and educational environment for the formation of ICT competence in the subjects of the educational process [9-19];

- clarification of methodological approaches in the formation of this phenomenon in the training of preschool education specialists [20-25].

First and foremost, the essence of the concept of "ICT competence" requires clarification. We state that today there is still no unanimous vision on the use of its definition and variations among scientists (most frequent is the definition of information and communication competence - IC competence as identical in meaning). The studied 
concept is presented in many ways, but based on the synthesis of different scientific positions, in our understanding, the following definitions of "ICT competence" are the most accurate, namely:

- integral quality of an individual, which indicates his/her ability to solve problems and typical problems that arise in real life situations, with the help of ICT, which contributes to the achievement of professionally significant goals [26];

- integral quality of personality, which includes motivation to master the relevant knowledge, the ability to solve problems in educational and professional activities with the help of computer technology and mastering the techniques of computer thinking [27];

- cognitive quality of an individual, which includes a set of knowledge, skills and abilities to perform various types of information and communication activities; the ability to use them in solving problems using the latest information technology [5, 28];

- structural component in the general system of the specialist's professional competence, a kind of stage in the formation of his/her information and communicative self-consciousness, which is manifested in information and communication culture, information and communication literacy, information and communication activities [12, 29];

- the ability of an individual to perform professional functions by searching through various means (through various media resources) for information to communicate, solve problems, gain new knowledge and generate solutions, which ultimately ensure his/her self-actualization $[30,31]$;

- a system of knowledge, skills, abilities, personal experience and personal qualities, which are aimed at effective and rational use of modern ICT, search, analysis and critical understanding of information, mastering rational methods of working with different types and sources of information to perform tasks in various spheres of life and confident orientation in the information space [32].

According to the given above, we emphasize that the ICT competence formation in the participants of the educational process is not only the accumulation of special knowledge, skills and abilities, but, above all, the development of information and communication selfconsciousness, ability to carry out relevant thinking (criticality, logic, argumentation, verification of information, etc.), which affects the formation of a holistic picture of the information world, in which the subject should be able to navigate. Based on the research results of the Ukrainian scientific school on the ICT competence formation, we note that in its structure one of the components is identified. It's the personal necessity to use ICT for the successful performance of professional duties $[33,34]$. The personal component strengthens the cognitive-active field of participants in the educational process, reveals their attitude to ICT, the desire to satisfy their own and professional interests, etc. Thus, despite the existing versatility of interpretation of the studied phenomenon, based on the generalization of different scientific positions, we offer the following working definition: integrated quality of an individual, which is the ability to navigate in the information space, receives information and operates it, performing professional tasks and meeting their own needs to the requirements of the modern high-tech information society.

A number of studies are devoted to the study of the peculiarities of the ICT competence formation of participants of the educational process. Scientists have proved that the use of ICT for the ICT competence formation of future professionals ensures the introduction of innovative educational technologies, promotes individualization of the subjects of the educational process of study, stimulates the intensity of independent search for information sources, increasing personal motivation [3-5, 32, 33, 35-44]. This clearly distinguishes the problem of figuring out various factors of influence, including psychological, on the ICT competence formation, because it is impossible to achieve high results without conscious understanding of the individual's role and importance in their own and professional activities.

\section{Psychological factors influencing the individual's ICT competence formation}

\subsection{Conceptual positions of determination of psychological factors influencing the individual's ICT competence formation}

Without diminishing the social, pedagogical and other factors influencing the ICT competence formation, we conceptually characterize only psychological. They determine individual achievements in mastering the relevant competence, promote personal growth, which is manifested in activities, communication skills, forms of behaviour and so on. Based on the study of different methodological approaches (system-activity, personalityoriented, integrative, environmental, competence, structural, etc.) to the formation of future specialists of the studied phenomenon and the analysis of scientific research, the following psychological factors of ICT competence were outlined: reflexivity, motivation, sociability [2, 20, 28, 45, 46]. (We present their essence in relation to the focus of scientific research - is an individual with pedagogical professional field of activity).

On the basis of reflexivity an analysis of a specific situation related to the use of ICT is taken place, the dynamics of its deployment and its own participation in it is occurred, achievements and shortcomings are evaluated, personal manifestations and professional qualities in this area are recognized. The reflective factor in the ICT competence formation is determined by the attitude of the individual to himself, to his achievements and miscalculations, to the results of their own practical activities and the development of plans for improvement or improvement in case of low self-esteem. Reflexivity as a psychological process of self-knowledge promotes the development of the ability to realize their own mistakes on the basis of awareness of ICT and scientific and methodological bases 
of their use, to follow the causes and results of their occurrence. This allows the individual to correlate the results of activities with certain reasons, to monitor them and draw appropriate conclusions, which require significant internal efforts. Reflexivity contributes to the expansion of personal experience, when the acquired knowledge about new ICT is transformed into skills and become automatic.

The motivational factor includes motives, purpose, the necessity of ICT application, aspiration to automation of the formed skills. Its development is based on the emergence of emotional adjustment to meet the need, which is to improve their personal position, aimed at carrying out both professional pedagogical activities and to obtain new knowledge to improve personal development. Motivation along its trajectory has a difficult way to implement the idea, which, above all, stimulates the emergence of an appropriate attitude to the situation: "goal - I want to master the usage of new ICT; motive - I want to find it, to study and assimilate; need - to implement in real practice; the result - is emotional satisfaction, personal self-realization and self-improvement". The motivational factor is fundamental to the system of values which an individual follows in mastering the knowledge, skills and abilities to use ICT. Motivation is a stimulus to activity, which always involves the use of volitional efforts, which are reflected in the regulation of behaviour, in the direction of activity and resilience of the individual to meet the need, such as looking for new information resources, etc.

Sociability as a psychological factor ensures the implementation of the transformation of the social requirement for contact in the created information and communication environment. It is manifested in the ability to establish interpersonal relationships using ICT, to choose the optimal style of information technology communication in different situations, to master the means of verbal and nonverbal communication. Sociability is manifested in the ability to communicate effectively with various participants in the educational process, if it is a professional activity or interest, in the case of personal needs, which contributes to establishing relationships with partners, the development of skills for constructive interaction. Communicative traits of an individual include the ability to listen, understand others, be tactful, be polite, and so on. The sociability of the subject ensures the success of his/her social interactions and promotes impartiality towards the views of others. Sociability testifies to the openness of the individual, the desire to continue cooperation. In polylogical communication, the individual activates all his/her communicative skills of conducting a substantive conversation/discussion concerning agreement with the participants of the interaction of their values and ideas, joint formulation of generalizations about the course and results of such activities.

\subsection{Basic psychological constructs of individual's ICT competence formation}

From the above it is clearly outlined that all the identified factors are closely intertwined and contain certain constructs of ICT competence. Regarding the factor of reflection, a cognitive and operative construct can be seen.
The cognitive construct should provide free mastery of personal skills of information processing and work with information and technical objects, which accordingly affect the skills of improving professional knowledge and skills, knowledge of interdisciplinary links, etc. The level of cognitive construction is determined by completeness, depth, systematic knowledge of the individual regarding the use of ICT. The operational construct characterizes the ability of a person to navigate in the information space, "get information and operate it in accordance with their own needs and requirements of modern high-tech society" [46]. The development of the operational construct testifies to the ability to regulate one's own cognitive activity freely and to select information from the whole set of information resources.

Revealing motivation as a factor in the formation of ICT competence the place of values and motivations in it are emphasized, which gives grounds to characterize their constructs that are part of it. The value construct in the ICT competence formation actualizes the stimulation of individual's creative manifestations in professional activity. It presupposes the presence of interest in professional activity, which characterizes an individual's need for knowledge, in mastering effective ways of organizing professional activity. Only perceived need as a value motivates us to perceive the results of our activities or behaviour rationally and objectively. As a result, there is an acceptance of the others position, the respect for their values and meanings formation, as well as awareness and acceptance of their own inner world - in the context of a critical dialogue with others and with themselves. The formation of a value construct is impossible without activating the volitional construct of the individual, when he/she is faced with the task of making an effort to master a new technology, to motivate him/herself to exercise self-control of newly obtained information and communication technical skills. Due to the development of the will, the individual is able to regulate their behaviour with others, can conquer their own spontaneity, taking into account their positions, ideas and so on. This ensures the development of common values for the application and extension of advanced ICT.

Sociability develops in the joint activities of an individual with other participants in the educational process during the ICT competence formation, which is necessarily reflected in the actions (behavioural reactions), discussion of new ideas and ways to implement them (creativity). Conative (behavioral) construct - is the active use of ICT and various gadgets in professional activities as a means of cognition and development of ICT competence, self-improvement and creativity, as well as the education of similar qualities in other participants of the educational process. And the creative construct creates favourable conditions for further modelling by the person of the innovative, non-standard program of the professional actions connected with application of ICT. The conative construct helps to determine the vector of one's own actions, the development of responsibility in making and implementing decisions on the implementation of ICT.

The presented constructs within the revealed psychological factors of ICT competence formation are consid- 
ered in definition of criteria and indexes in research of the specified phenomenon.

\subsection{Presentation of criteria, indexes and levels of individual's ICT competence formation}

We consider it worthwhile to analyze the existing developments of scientists regarding the explication of the criteria for the ICT competence formation. The issue raised has diversity of scientific views. The most relevant to the stated topic in the study of various areas of ICT competence (including IC competence), in our opinion, are the following criteria:

- Definition (Df), Access (Ac), Evaluation (E), Administration (Ad), Integration (I), Creation (C), Delivery (D1) [45];

- motivational-value, cognitive-contentive, operationaltechnological, reflexive-evaluation [47];

- informational, motivational, activity [48];

- axiological, epistemological, praxeological [49];

- cognitive, social-communicative, gnosticdevelopmental, activity-technological [50].

Thus, based on the generalization of the analyzed scientific views on the author's conceptual provisions, the following criteria and indexes of ICT competence formation are determined.

- Cognitive-operational: the available knowledge and operational skills that reflect the degree of ICT awareness and their conscious use in professional activities; ability to reflect, analyze and evaluate their own both cognitive and practical activities; awareness of the selection and processing of information from the whole set of information resources; ability to determine the expediency of using certain ICT in professional activities; development of the ability to develop and apply ICT in professional activities.

- Value-volitional: the presence of interest in mastering ICT and their persistent development; satisfaction of one's own ambitions regarding the need to form ICT competence; formation of a value attitude to professional and pedagogical activity with the use of ICT; awareness of personal meaning and significance of ICT competence; strong-willed persistence in striving for professional self-improvement in relation to mastering ICT; development of ability to carry out purposeful search of information and technological resources; formation of the ability to act balanced, guided by rational motives, and to objectively perceive the value positions of others; regulation of the balance between their own desires, needs, opportunities and motivation to achieve high performance in professional activities for the use of ICT.

- Conative-creative: the use of ICT in various forms using the latest methods of working with them, the development of the ability to overcome difficulties in mastering ICT, using creative approach; the ability to establish emotionally positive relationships between all participants in the educational process in an information and communication environment (places of professional teaching); ability to professionally use the means of ICT to establish communication, exchange and spreading advanced ideas in the application of ICT; ability to create an atmosphere of creativity and positive attitude between the subjects of joint activities; the desire to implement innovations that stimulate the ICT competence development.

The outlined criteria and indicators made it possible to characterize the following levels of ICT competence formation: high, medium and low.

- The high level is defined as the possession of profound knowledge in the field of ICT and the ability to use them with the use of modern scientific and methodological tools; developed ability to freely regulate their own cognitive and exploratory activities in mastering the latest forms and methods of professional activity with the use of ICT; striving for self-improvement in the use of information tools in the work of the participants of educational process. Respondents with a high level of mobility in the establishment of friendly relations are able to regulate their own ambitions, consider the values of others; are able to create an atmosphere of creativity and positive attitude in their own behaviour. They tend to thoroughly analyze the possibilities of ICT, are able to technologically represent their own professional activities in relation to the use of ICT, giving it adequate self-assessment and quickly identify problems in overcoming difficulties in mastering skills that stimulate ICT competence formation.

- The medium level is characterized mainly by mastered knowledge in the field of ICT and the average desire to use them in professional activities with the introduction of modern guidelines; sufficient possession of the ability to regulate their own behaviour, establish contacts and communication with participants of the educational process. Representatives belonging to the medium level group have the ability to establish trusting professional relationships, although significant errors in the use of ICT tools may be assumed. Usually it is not difficult for them to create an atmosphere of creativity and organize activities with the use of ICT, but they do not initiate it on their own. Self-assessment takes place in urgent situations, but they seek to overcome difficulties with group support in the process of mastering ICT. Medium-level respondents have the ability to analyze the possibilities of ICT, although they do not demonstrate a desire to present their own experience of ICT competence technologically.

- The low level is manifested in the lack of knowledge in the field of ICT implementation, their selectivity, lack of desire to find innovative approaches and tools to be used in their own professional activities; difficulties of free behavioural regulation aimed at the creative selection process and use of information and software tools in working with participants in the educational process. Respondents belonging to this group find it difficult to establish contact, they defend their own ambitions, they 
are reluctant to show willpower. They do not demonstrate an independent desire to use ICT tools professionally, work in a reproductive atmosphere. The implementation of adequate self-esteem is characterized by various obstacles from others, make mistakes in identifying problems and lack initiative in overcoming difficulties in mastering ICT. They have a poorly developed ability to analyze the possibilities of ICT and their use, usually avoid the technological presentation of their experience in the ICT competence formation.

\section{Methodology of research of the influence of psychological factors on the individual's ICT competence formation}

Research tools. The main tool of the empirical research was the use of a written questionnaire - filling out a questionnaire "Personal need for ICT competence in professional activity" in the author's modification [49]. The purpose of its use is to diagnose the influence of psychological factors on the ICT competence formation of teachers of the first (preschool) component of the Ukrainian educational system - teachers of preschool education, who are also applicants for educational services, and, in particular, study in specialty 012 "Preschool education" and, respectively, work in the specialty. The choice of such a research group is due to the fact that it is from the moment of individual's formation (and this basis is formed in preschool childhood), they must obtain all the necessary competencies for life, among which the main one today is ICT competence. The level of this competence of preschool teachers' formation will directly influence its development in children.

The content of the questions was grouped into three semantic blocks that correspond to the essential substantiation of the presented psychological factors: reflexivity, motivation, sociability. The analysis was also based on methodological approaches suggested by modern scientists [26, 28, 29, 47]. The main thesis of the empirical study of determining the influence of psychological factors on the level of ICT competence was that the latter "is based on sets of relevant understandings, knowledge, attitudes and skills", the assimilation of which occurs during university studies and immediately transferred to real practice, because part-time students are working in the field of teaching [2].

Data collection procedures and methods of analysis. The collection of empirical materials took place during the spring session of students 2019/2020 academic year, the processing of the results took place in September - October 2020, generalization and analysis - during November - early December 2020.

Description of study samples. The experiment involved students of 1-4 years of study of distance learning, who got the first (Bachelor's) level of higher education, as well as students of 1-2 years of study of distance learning, who got the second (Master's) level of higher education (field of knowledge 01 Education / Pedagogy) and study in the specialty 012 "Preschool Education" in Hryhorii Skovoroda University in Pereiaslav and The Bohdan Khmelnytsky National University of Cherkasy (Ukraine). The educational and professional training programs of both levels provide for the study of relevant subjects "Information Technology in Education", "Fundamentals of Digital Media Literacy" etc. Given the specifics of the study, only part-time students were united in research groups not by course, but by experience in teaching (experience in the specialty) in order to determine what are the psychological factors influencing the ICT competences formation are prevalent depending on the acquired knowledge and their direct application in practice. The total number of students-practicing in teaching in preschool institutions selected for the experiment was 187 ones. The first group consisted of those who had experience of professional activity from 0 to 5 years -67 people, the second group - those whose experience is from 5 to 10 years -61 people and the third - those who had over 10 years of experience -59 people.

The determination of research groups in accordance with the term of experience together with the process of getting education (Bachelor's and Master's degrees) was carried out taking into account that: during 5 years of professional activity the teacher gains experience, learns to evaluate his/her own results; from 5 to 10 years there formation of individual style of pedagogical activity takes place and professional maturity increases; those who have over 10 years of experience, as a rule, start to achieve professional skills and high professionalism.

\section{Results of research of the influence of psychological factors on the individual's ICT competence formation}

Based on the results of the written survey "What is your personal need for the ICT competence formation in professional activity?" from the participants of the survey $(n=187)$ it was found that all forms are completed and the available data can be analyzed quantitatively and qualitatively. All quantitative results of the influence of psychological factors (reflexivity, motivation, sociability) at the level of ICT competence formation in part-time students who are teaching in preschool educational establishments are presented in figures 1-3. Thus, figure 1 presents quantitative indexes of the reflexivity impact (analysis of the questions of the first block of the questionnaire) at the level of ICT competence formation.

As it is presented in figure 1, the influence of the psychological factor of reflexivity at the level of ICT competence was recorded with the following results: respondents of the 2nd group had a high level (work experience $-5-10$ years), namely $21.31 \%(n=13)$, in second place were those who were in the 3 rd group (working in the specialty for over 10 years $)-16.95 \%(n=10)$ and with a slight lag behind them were the representatives of the 1 st group (work experience $-0-5$ years) $-16.42 \%(n=11)$. Part-time students of high-level were widely aware of the use of ICT in their professional activities. They were focused not only on the formation of computer literacy, but 


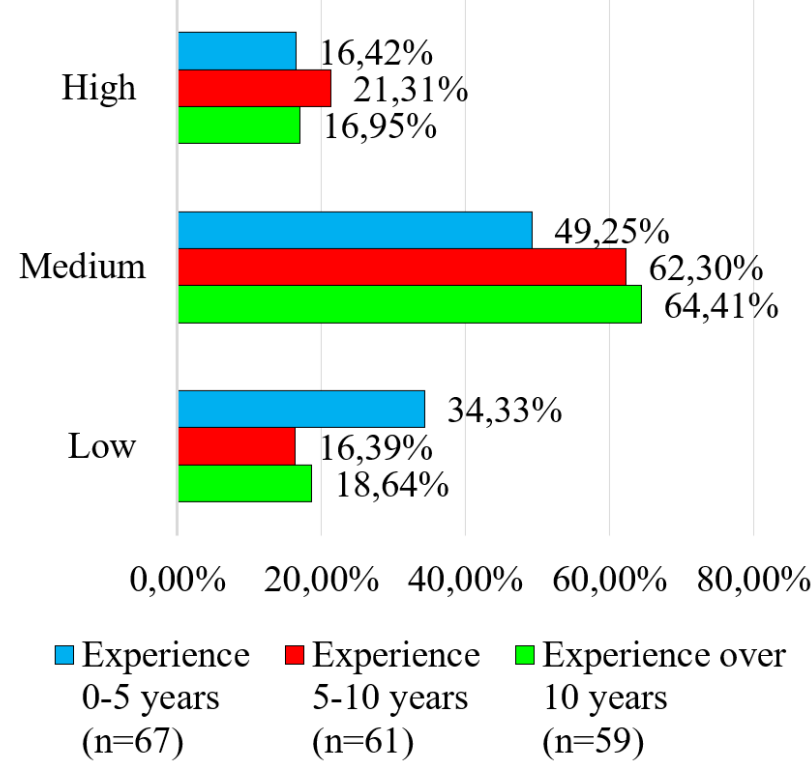

Figure 1. Quantitative indexes of the influence of the psychological factor reflexivity at the level of ICT competence formation

also on the development of the ability to make optimal decisions in difficult situations, the development of skills and abilities to work independently on the processing of educational and scientific information, self-control etc. Their reflectivity is manifested in the high ability to analyze their own capabilities of ICT usage. They constantly carry out the process of self-knowledge, which is manifested in adequate self-esteem. Their attitude to the problems that arise during the acquisition of ICT are constructs. They comprehend them and make the right conclusions. The decrease in the high level of the respondents of the 3rd group compared to the 2nd group was unexpected, which is explained by the growth of the number of medium-level respondents from this group and their weakening of self-analysis due to large work experience.

The most significant indicators of the impact of reflexivity were found at the medium level of ICT competence. A significant number of such respondents were those who were in the 3rd group (experience over 10 years) $-64.11 \%$ $(n=38)$, a small decrease $(-2.11 \%)$ was recorded in the subjects of the 2nd group (experience of 5-10 years) $-62.30 \%$ $(n=38)$ and the least of those who had an average level in the 1st group (experience of $0-5$ years) $-49.25 \% \quad(n=33)$. It is typical for them only in case of necessity, as they answered to the questions in the questionnaire, to reflect on their own results in terms of knowledge in the field of ICT and their application in real practice of working with children in preschool education. They self-assess their achievements or miscalculations in the possibilities of using ICT when an urgent situation arises, although they operate such skill quite well. These respondents periodically identify the reasons for the decrease in their own activity in finding information about information resources and their implementation in their professional activities. The results demonstrated that the influence of the psychological factor of reflexivity tended to increase due to the increase in the length of students' working experience.

The low level in the largest quantity was diagnosed in the 1 st group of respondents (experience from 0 to 5 years) $-34.33 \%$ ( $n=23)$, almost halved the number of those who had such a level in the subjects of the 3rd group (experience over 10) years) $-18.64 \%(n=11)$ and in the 2 nd group (experience of 5-10 years) - $16.39 \%(n=10)$, which is even $(-2.25 \%)$ less than in the respondents of the $3 \mathrm{rd}$ group. Respondents who had a low level are characterized by insufficient analysis of the implementation of ICT, they do not care about the lack of knowledge or lack of personal experience in such area of professional activity. However, when it came to personal needs, such as the mobile applications usage, they replied that they self-analyzed their own knowledge and skills, giving them self-assessment and identifying gaps that required improvement. Thus, the influence of reflexivity of ICT competence formation had the dynamics of virtually direct dependence on the teaching experience. This is due to the ability to comprehend and analyze their interactions with participants in the educational process, to draw the right conclusions, to selfregulate behaviour, which has been developing over the years of pedagogical practice.

Thus, according to the results of the experiment, there is an increase in the psychological factor of reflexivity in the ICT competence formation in part-time students who had experience of more than 5 years ( 2 nd and 3 rd groups). This is due to the more developed over the years of pedagogical practice the ability to comprehend and analyze their interactions with participants in the educational process. Respondents with little experience (up to 5 years) the 1st group were less able to reflect and draw the right conclusions.

Motivation was also studied as a psychological factor influencing the ICT competence formation. Figure 2 presents quantitative indicators of the impact of motivation (analysis of the second block of the questionnaire) at the level of ICT competence formation in part-time students of specialty 012 "Preschool Education".

According to the figures given in figure 2 it is understandable that the results of the influence of the psychological factor motivation on the ICT competence formation in subjects with different lengths of teaching experience in most cases are distributed between medium and high levels. Respondents who have high level, they are $40.30 \%$ $(n=27)$ from the 1st group (experience up to 5 years) and $38.98 \%(n=23)$ - from the 3rd group (experience over 10 years). At the same time, comparable with these groups, such respondents are less in number in the 2nd group (experience of $5-10$ years $)-27.87 \%(n=17)$. In their answers, respondents of high-level identified that it is extremely important to persistently search for innovative information tools in working with children, to intensify their own cognitive activity by studying in additional courses, which requires considerable willpower. Therefore, they have a high level of motivation to improve their ICT competence formation and thus work on self-improvement. This is most typical for the respondents of the 1st group, who as young specialists strive to establish themselves in the profession 


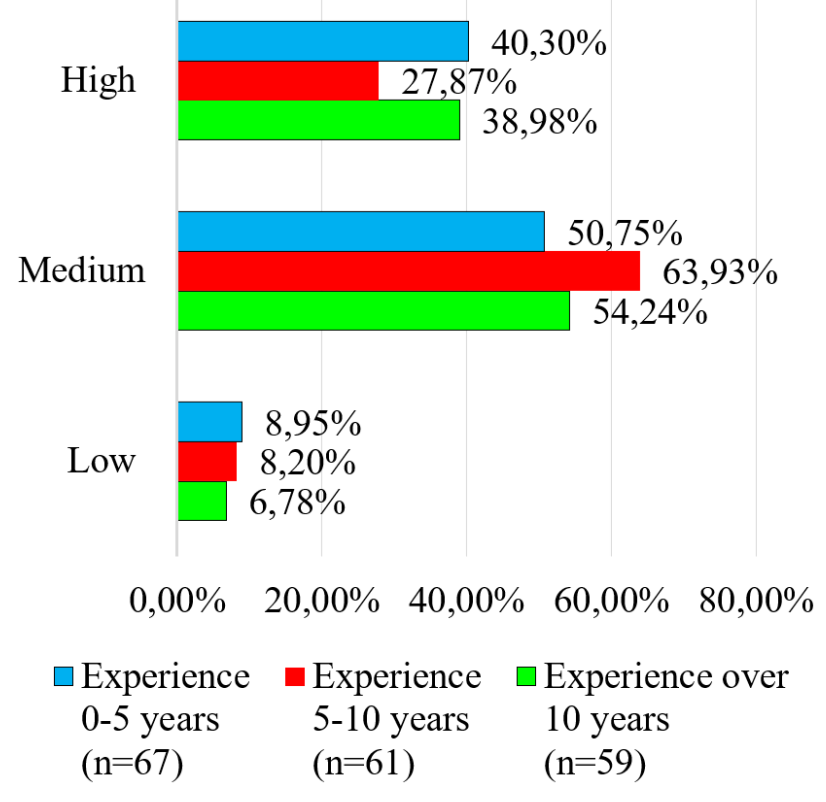

Figure 2. Quantitative indexes of the influence of the psychological factor motivation at the level of ICT competence formation

as much as possible. This is also true for part-time students with over 10 years of experience, who, having experience, are able to regulate their own ambitions, but are constantly working to improve their own professionalism. The decrease in the number of respondents with a high level in the 2nd group was an unexpected result (due to this the number in medium level increased), which can be explained as follows: having some professional achievements, these respondents believe that they can use traditional ICT in their own activities without excessive effort in finding new things.

As in the diagnosis of the reflexivity influence, the most significant indicators of the psychological factor motivation are found at the medium level of ICT competence formation. In particular, the largest number of such respondents $-63.93 \%(n=39)$ were representatives of the 2nd group (experience of 5-10 years), the dynamics of reducing this indicator to $54.24 \%(n=32)$ was recorded in the subjects of the 3rd group (experience over 10 years) and even lower $-50.75 \%(n=34)$ in those who were in the 1 st group (experience from 0 to 5 years). Thus, the recorded facts demonstrate that the influence of motivation as a psychological factor in the ICT competence formation at the average level increased in respondents of the 2nd group, but decreased in the subjects of the 3rd group, compared with quantitative indicators in the 1st group. Respondents defined their attitude to the implementation of modern guidelines for the use of ICT as "desire when the need arises". Motivation increases with the getting experience, when a certain stage of professional growth takes place. The subjects, who had an average level, noted that they have sufficient ability to arbitrarily regulate their own behaviour when a situation of nervous tension arises, but the motive to gain new knowledge and new experience in the use of ICT. In part, they seek for help from colleagues because support is important to them.

The low level was recorded in $8.95 \%(n=6)$ of respondents from the 1st group (experience of 0-5 years), almost the same as the previous ones $-8.20 \%(n=5)$ in the subjects of the 2nd group (experience of 5-10 years) and the lowest of all $-6.78 \%(n=4)$ in those who were in the 3rd group (experience over 10 years). Their low motivation was due to the lack of necessity to look for innovative approaches in the application of ICT, as well as effective tools for their use in their own professional activities. For those who belong to this group, it is difficult to regulate their behaviour arbitrarily. They noted it in the answers to the questionnaire, noting that being absorbed by one type of work, they do not think about the need to synthesize it with ICT.

In general, it can be concluded that motivation is manifested mainly at high and medium levels in the ICT competence formation. The number of respondents with a low level is insignificant and practically does not differ significantly among respondents of all three groups.

The question of clarification the influence of sociability as a psychological factor in the ICT competence formation deserved attention. Figure 3 contains quantitative indicators of the impact of sociability (analysis of the questions of the third block of the questionnaire) at the level of ICT competence formation in part-time students.

The data presented in figure 3, displays that more than half of the all three groups being under study had a high level of ICT competence in relation to the influence of the psychological factor sociability. The largest number of respondents of this level was recorded in the 2nd group (experience $5-10$ years $)-68.85 \% \quad(n=42)$, followed by the 1 st group (experience $0-5$ years) $-61.19 \%(n=41)$ and the least was in the 3rd group (experience over 10 years) $57.63 \%(n=34)$. They are focused on mobility and friendliness in relations with others, seek to discuss and jointly search for innovations in the use of ICT, openly express their positions and take into account the suggestions and values of colleagues. The influence of sociability is manifested in a positive attitude to the use of creative ideas in the joint projects creation (for example, it is recorded in the answer: "When the "Educational Bridge" was held between the preschool institution with which the cooperation agreement was concluded, the video broadcasting service Zoom and Google Classroom were used jointly"). Thus, the presence of sociability eliminates or minimizes the possible conflicts with others and promotes activation in the technological presentation of their own professional activities. However, in the 3rd group, comparable to the 1 st and 2 nd, the high level decreased, due to an increase in the number of respondents with the medium level. The reason for this, as it turned out, was a certain weakening of contact with colleagues due to the creation of their own files of information resources.

The medium level of ICT competence in relation to the influence of sociability as a psychological factor was demonstrated by the largest number of respondents in the 3rd group (experience over 10 years) - 33.90\% ( $n=20)$, almost the same was recorded in the 1 st group (experience 


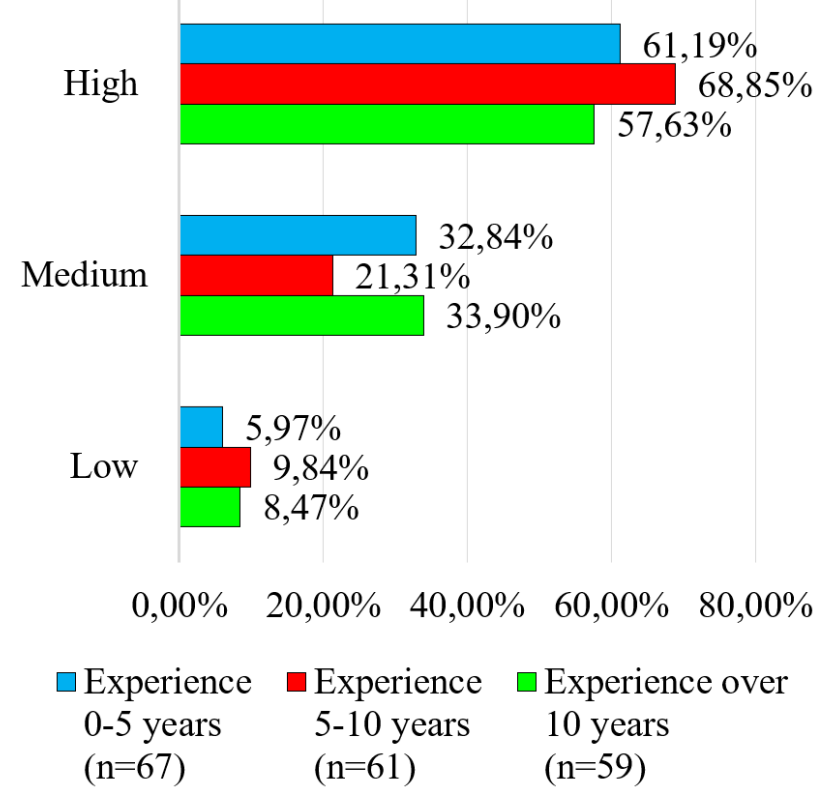

Figure 3. Quantitative indexes of the influence of the psychological factor sociability at the level of ICT competence formation

of $0-5$ years), which is $32.84 \%$ ( $n=22)$ and the least in the 2nd group (experience of $5-10$ years) $-21.31 \%(n=13)$. These respondents have developed the ability to communicate and establish contacts with participants of the educational process, however, it happens that they are not always able to convince them in the correctness of their own position. They easily establish trusting professional relationships, creating an atmosphere of creativity and ease. In the answers to the questionnaires, they noted that despite of the fact that they can do it easily, they do not often demonstrate initiative in the use of ICT in professional activities. Having their own achievements do not seek to technologically present their own developments in the use of ICT.

The low level is typical for $9.84 \%(n=6)$ respondents from the 2nd group (experience 5-10 years), 8.47\% ( $n=5$ ) of the subjects of the 3 rd group (experience over 10 years) and $5.97 \%(n=4)$ from the first group (experience 0-5 years). As we can see, the highest percentage is recorded in the 2nd group, it is obvious that due to self-affirmation in professional activities and the available little life and professional experience there is an overestimation. Representatives of the 3rd group had similar results, which probably testify to their excessive confidence in the correctness of their own positions. Respondents of the low level only situationally make contacts, dominate in their preferences, despite of the opinion of other participants in the educational process, demonstrate their own ambitions. As they indicated in the answers to the questionnaires, they do not spend time discussing non-standard creative approaches, but use information and software tools according to a pattern. They are characterized by avoidance of technological presentation of their experience in the ICT competence formation.
Thus, communicativeness as a psychological factor in the obtained quantitative indicators has the greatest impact on the ICT competence formation in part-time students working in the specialty. No significant difference in indicators according to length of working experience was found. A slight difference in the growth of the high level and the decrease of the average was recorded among the respondents of the 2nd group, which should be interpreted as a fact of self-affirmation in pedagogical activity and achievement of professional maturity.

Thus, the study of the influence of psychological factors: 1) reflexivity; 2) motivation; 3) sociability in the ICT competence formation of the studied groups showed that the third dominates the most, and the first two were with average data. According to the results of the survey analysis, some dependence of the gained experience of pedagogical activity in accordance with the definition of the role of psychological factors of the studied phenomenon is established. In particular, for the 1st group (experience $0-5$ years) the most important were motivation and sociability, for the 2nd group (experience 5-10 years) - reflexivity and sociability, and for the 3rd group (experience over 10 years) - reflectivity and motivation. The obtained data represent only a limited sample of participants in the empirical study from part-time students on speciality 012 "Preschool Education" from 2 Ukrainian universities, so the results cannot be generalized, and the study of the scientific problem will be carried on.

\section{Conclusion}

1. Due to the fact that the problem of readiness of the educational system specialists, and first of all, its first component - preschool education, scientists emphasize the urgent necessity to form ICT competence as a necessary condition for professional stability, orientation in the information space, development of the ability to operate data based on the application of modern ICT in accordance with the requirements of the labour market and for the effective performance of professional duties.

2. Professional training of preschool education specialists includes the ICT competence formation as a multifaceted psychological phenomenon, due to the requirements of modern information society, which requires a competitive, mobile and competent professional, able to creatively and unconventionally solve problems of educational process, ready to apply innovations in their own pedagogical activities in the conditions of a modern preschool educational institution. Important components in the ICT competence formation of students on speciality 012 "Preschool Education" provide knowledge about ICT, development of skills in their application, stimulating interest and desire to seek innovation, supporting the desire for practical testing of creative ideas in the information space. It determines the personal component in the structure of ICT competence. Accordingly, ICT competence 
in the study was considered as an integral quality of personality, which determines its ability to navigate in the modern dynamic information space and accumulate a system of special knowledge, skills and abilities that have a direct impact on the formation of individual's information and communication consciousness, development of communicative qualities and implementation of creative approaches in the use of ICT in the conditions of work in the preschool educational institutions.

3. In the process of developing conceptual positions it is taken into account that ICT competence of students who study part-time (Bachelor's and Master's levels) and are already specialists in preschool education has specific features. It is related to the fact that they implement personal, professional, informational, communicative and technological potentials comprehensively. Based on the theoretical substantiation, the following psychological factors influencing the ICT competence formation, in particular, reflexivity, motivation, sociability, which contain the following basic constructs (two for each of them): cognitive, operational, value, volitional, conative, creative. These constructs were taken as a basis in determining the criteria for the ICT competence formation. These are outlined: cognitive-operational, valuevolitional, conative-creative with appropriate indicators for each. The total synthesis gave grounds to characterize the levels of ICT competence formation: high, medium, low.

4. An empirical study of the influence of psychological factors on the ICT competence formation on the basis of a written survey of respondents allowed to determine the essential dominance of each of them, namely: reflexivity, motivation, sociability in each of the study groups, which included part-time students according to the length of professional activity. Indicators of the impact of reflexivity and motivation were at the medium level, and sociability - at a high level - in all groups of subjects (1st - from 0 to 5 years; 2 nd - from 5 to 10 years; 3 rd - over 10 years). In conclusion, we see the need to increase the influence of the first two psychological factors at the level of ICT competence formation.

5. Thus, in the ICT competence formation emphasis should be shifted, first of all, to determine the psychological basis of the studied phenomenon, taking into account the formation of information and communication self-awareness, developing students' ability to use acquired knowledge of modern ICT, which will enrich their professional experience. The high level of ICT competence will distinguish an individual, from others as the one who feels confident in the boundless, dynamic, constantly changing world of information and has such qualities as mobility, purposefulness, persistence, adaptability, ability to quickly update their knowl- edge and generate new ideas, constructively solve difficulties and work productively in a team. It is these qualities that ensure the competitiveness of preschool education professionals in the labour market, a comfortable existence in the information society, successful self-realization and generally increase the level of professional growth.

\section{References}

[1] Zakon Ukrainy "Pro osvitu” (Law of Ukraine "On Education”) (2017), https://zakon.rada.gov . ua/laws/show/2145-19\#Text

[2] Information and communication technology (ICT) competence (2010), https://www.kattekrab. net/sites/default/files/ICT-concept.pdf

[3] A. Creer, Journal of New Approaches in Educational Research 7, 131 (2018)

[4] A. Otterborn, K. Schönborn, M. Hultén, International Journal of Technology and Design Education pp. 717-737 (2019)

[5] O.N. Machekhina, Espacios 38, 26 (2017)

[6] A. Martin, J. Grudziecki, Innovation in Teaching and Learning in Information and Computer Sciences 5, 249 (2006)

[7] N. Balyk, Y. Vasylenko, G. Shmyger, V. Oleksiuk, O. Barna, CEUR Workshop Proceedings 2732, 1097 (2020)

[8] O. Yaroshenko, O. Samborska, A. Kiv, CEUR Workshop Proceedings 2643, 94 (2020)

[9] R. Romero-Tena, R. Barragán-Sánchez, C. LlorenteCejudo, A. Palacios-Rodríguez, Sustainability 12, 4782 (2020)

[10] S. Ghavifekr, W.A.W. Rosdy, IJRES 1, 175 (2015)

[11] X. Liu, J. Pange, Journal of Computers in Education 2, 61 (2015)

[12] M. Moiseienko, N. Moiseienko, I. Kohut, A. Kiv, CEUR Workshop Proceedings 2643, 60 (2020)

[13] Z. Bakum, K. Morozova, Metallurgical and Mining Industry 7, 164 (2015)

[14] M. Popel, S. Shokalyuk, M. Shyshkina, CEUR Workshop Proceedings 1844, 327 (2017)

[15] M. Rassovytska, A. Striuk, CEUR Workshop Proceedings 1844, 348 (2017)

[16] A. Striuk, M. Rassovytska, S. Shokaliuk, CEUR Workshop Proceedings 2104, 412 (2018)

[17] S. Lytvynova, O. Burov, O. Slobodyanyk, CEUR Workshop Proceedings 2393, 107 (2019)

[18] Y. Modlo, S. Semerikov, P. Nechypurenko, S. Bondarevskyi, O. Bondarevska, S. Tolmachev, CEUR Workshop Proceedings 2433, 413 (2019)

[19] K. Vlasenko, O. Chumak, V. Achkan, I. Lovianova, O. Kondratyeva, Universal Journal of Educational Research 8, 3527 (2020)

[20] S.I. Semchuk, S.M. Gavriliuk, O.H. Butenko, Information Technologies and Learning Tools 66, 24 (2018) 
[21] C. Buabeng-Andoh, Contemporary educational technology 3, 36 (2012)

[22] A.B. Mirete, J.J. Maquilón, L. Mirete, R.A. Rodríguez, Sustainability 12, 4842 (2020)

[23] P. Miralles-Martínez, C.J. Gómez-Carrasco, V.B. Arias-González, O. Fontal-Merillas, Comunicar 61, 45 (2019)

[24] T. Kolomoiets, D. Kassim, CEUR Workshop Proceedings 2257, 237 (2018)

[25] O. Yankovych, V. Chaika, T. Ivanova, K. Binytska, I. Kuzma, O. Pysarchuk, H. Falfushynska, CEUR Workshop Proceedings 2433, 126 (2019)

[26] K. Aesaert, J. van Braak, Information and Communication Competences for Students (Springer International Publishing, Cham, 2018), pp. 255-269, ISBN 978-3-319-71054-9

[27] D.Z. Dumpit, C.J. Fernandez, International Journal of Educational Technology in Higher Education 14, 5 (2017)

[28] G. Almerich, N. Orellana, J. Suárez-Rodríguez, I. Díaz-García, Computers \& Education 100, 110 (2016)

[29] F. Lehner, M.W. Sundby, ICT Skills and Competencies for SMEs: Results from a Structured Literature Analysis on the Individual Level (Springer International Publishing, Cham, 2018), pp. 55-69, ISBN 978-3-319-63257-5

[30] J. Gil-Flores, J. Rodríguez-Santero, J.J. TorresGordillo, Computers in Human Behavior 68, 441 (2017)

[31] A. Sangrà, M. González-Sanmamed, ALT-J 18, 207 (2010)

[32] J. Kubrický, P. Částková, Procedia - Social and Behavioral Sciences 186, 882 (2015), the Proceedings of 5th World Conference on Learning, Teaching and Educational Leadership

[33] V.Y. Bykov, M.P. Leshchenko, Information Technologies and Learning Tools 53, 1 (2016)

[34] M.I. Zhaldak, V.M. Franchuk, N.P. Franchuk, Journal of Physics: Conference Series 1840, 012001 (2021)
[35] E. Fernández, J.J. Leiva, E.J. López, Campus Virtuales 6, 79 (2017)

[36] O. Chorna, V. Hamaniuk, A. Uchitel, CEUR Workshop Proceedings 2433, 294 (2019)

[37] I. Kholoshyn, O. Bondarenko, O. Hanchuk, E. Shmeltser, CEUR Workshop Proceedings 2433, 403 (2019)

[38] V. Ustinova, S. Shokaliuk, I. Mintii, A. Pikilnyak, CEUR Workshop Proceedings 2433, 308 (2019)

[39] O. Lavrentieva, L. Rybalko, O. Tsys, A. Uchitel, CEUR Workshop Proceedings 2433, 102 (2019)

[40] P. Nechypurenko, V. Stoliarenko, T. Starova, T. Selivanova, O. Markova, Y. Modlo, E. Shmeltser, CEUR Workshop Proceedings 2547, 156 (2020)

[41] V. Pererva, O. Lavrentieva, O. Lakomova, O. Zavalniuk, S. Tolmachev, CEUR Workshop Proceedings 2643, 321 (2020)

[42] M. Syvyi, O. Mazbayev, O. Varakuta, N. Panteleeva, O. Bondarenko, CEUR Workshop Proceedings 2731, 369 (2020)

[43] N. Valko, V. Osadchyi, E3S Web of Conferences 166, 10021 (2020)

[44] K.V. Vlasenko, O.O. Chumak, I.V. Sitak, V.V. Achkan, O.M. Kondratyeva, Journal of Physics: Conference Series 1840, 012008 (2021)

[45] O. Kuzminska, M. Mazorchuk, N. Morze, V. Pavlenko, A. Prokhorov, CEUR Workshop Proceedings 2104, 366 (2018)

[46] S.I. Semchuk, N.S. Skripnik, B.I. Semchuk, Information Technologies and Learning Tools 67, 13 (2018)

[47] F. Chen, N.V. Gorbunova, A.R. Masalimova, J. Bírová, EURASIA Journal of Mathematics Science and Technology Education 13, 4765 (2017)

[48] I.V. Sereda, N.V. Savinova, N.V. Stelmah, O.H. Biliuk, Information Technologies and Learning Tools 74, 56 (2019)

[49] H.M. Fedoruk, Ph.D. thesis, Vinnytsia Mykhailo Kotsiubynskyi State Pedagogical University (2015)

[50] S.I. Semchuk, Ph.D. thesis, Pavlo Tychyna Uman State Pedagogical University (2017), https:// nauka.udpu. edu.ua/avtoreferat-14/4 